Artigos

Volume 10 - $2020 \mid$ n. 5

\title{
Montantes e Gastos Anuais de Escolas Públicas com os Recursos do PDDE: estudo de caso em uma escola municipal (2007-2016) e uma escola estadual de São Paulo/SP (2006-2016)
}

Clarissa dos Santos Bitencourth

Fernanda Dayane Bezerra Gomes

Rubens Barbosa de Camargo

Universidade de São Paulo (USP), São Paulo/SP - Brasil

\section{Resumo}

O artigo buscou investigar o Programa Dinheiro Direto na Escola (PDDE) em duas escolas, uma da rede municipal de São Paulo e outra da rede estadual de São Paulo de 2006 a 2016. Por meio de instrumentos distintos, levantou-se e analisou-se o montante recebido, o tipo de gasto (consumo e capital), o destino do montante de cada escola, a quantidade de alunos e repasses recebidos do PDDE anualmente. As resoluções do FNDE, que alteraram a fórmula de cálculo, os valores devidos e a quantidade de repasses foram aferidos por meio dos valores repassados e recebidos. Os aportes teóricos seguiram os trabalhos de Mafassioli (2017), Batista (2018) e Viana $(2009,2010,2015)$. Observou-se que os maiores valores recebidos por ambas as escolas foram nos anos de 2011, 2013 e 2016; que cada escola recebeu o valor do repasse de custeio e capital de acordo com suas necessidades; que a escola da rede municipal recebeu somente um repasse e a escola estadual recebeu mais de um repasse nos anos de 2011 e 2016.

Palavras-chave: Recursos Financeiros Descentralizados. PDDE. Escola Pública.

\section{Annual Amounts and Expenses of Public Schools with PDDE}

\section{Resources: case study in a municipal school (2007-2016) and a state school in São Paulo / SP (2006-2016)}

\begin{abstract}
This paper aimed to investigate the Direct Money in School Program (PDDE) in two schools: one under the city of São Paulo administration and the other under the state of São Paulo, from 2006 to 2016. Using different instruments, it was collected and analyzed the amount received, the type of expenses (regarding consumption and capital), the destination of the amount of each school. the number of students and resources received from the PDDE annually. The FNDE resolutions, which changed the calculation formula, the amount due and the resources received, were measured through the amounts passed on and received. The theoretical contributions followed the works of Mafassioli (2017), Batista (2018) and Viana $(2009,2010,2015)$. It was observed that the highest amounts received by both schools happened in 2011, 2013 and 2016; that each school received the amount of the transfer of funding and capital according to their needs; and that the municipal school received only one transfer, while the state school received more than one transfer in 2011 and 2016.
\end{abstract}

Keywords: Decentralized Financial Resources. PDDE. Public School. 
Montantes e Gastos Anuais de Escolas Públicas com os Recursos do PDDE

\section{Introdução}

Este trabalho consiste na sintetização de duas pesquisas de Iniciação Científica (IC), realizadas em uma escola da rede municipal de São Paulo (PMSP) e outra realizada numa escola da rede estadual de São Paulo, referentes ao Programa Dinheiro Direto na Escola (PDDE), de origem federal, vinculado ao Fundo Nacional de Desenvolvimento da Educação $(F N D E)^{1}$ do Ministério da Educação (MEC), que viabiliza recursos financeiros para escolas públicas de forma descentralizada, a fim de realizar demandas de manutenção escolar, pedagógicas e compra de material permanente.

Ambas as pesquisas estudam diferentes programas de recursos financeiros destinados à escola pública, e com abrangência metodológica distinta, pois, na escola municipal existem recursos financeiros de origem federal (PDDE) e outros recursos provenientes da prefeitura de São Paulo, enquanto a pesquisa realizada na escola estadual de São Paulo abrange recursos de origem federal (PDDE) e os recursos provenientes do governo do estado de São Paulo.

As pesquisas realizaram aplicação de instrumentos para levantamento de dados junto às escolas participantes, bem como analisaram a gestão financeira escolar, de forma a compreender as origens dos recursos financeiros que chegam à escola pública, os montantes, os destinos por ela aplicados e os processos de participação e decisão envolvidos em sua execução financeira. $O$ intuito de ambas as pesquisas foi o de prosseguir com as análises propostas pelos referidos trabalhos, dando continuidade aos levantamentos realizados, atualizando o referencial teórico e documental da temática, de forma a ampliar a amostra da pesquisa e estender o período histórico abordado, possibilitando, desse modo, novas análises e contribuições.

Buscou-se também a revisão de literatura de outros trabalhos sobre a temática, como a dissertação de mestrado de Mariana Peleje Viana (2015), Recursos financeiros descentralizados para a escola pública: uma política necessária; a tese de doutorado de Andréia da Silva Mafassioli (2017), Programa Dinheiro Direto na escola (Re)formulações e implicações na gestão escolar e financeira da educação básica (1995-2015) e a dissertação de Pablo Aguiar Castro Batista (2018), Descentralização financeira para as escolas da educação básica pública: uma análise do PDDE na escola estadual cidade modelo no período de 2012 a 2015.

Neste trabalho, apresentaremos o que as duas pesquisas têm em comum quanto ao levantamento e análise de dados sobre o PDDE e suas aplicações na denominada Escola A, jurisdicionada à Secretaria Municipal de Educação de São Paulo, que atende o Ensino Fundamental I E II, e a Escola B, vinculada à Secretaria de Educação do Estado de São Paulo, que atende o Ensino Fundamental I.

1 FNDE: órgão executor de políticas educacionais de assistência do MEC a estados e municípios, entre elas, o PDDE. Responsável pela normatização complementar à legislação, abertura de contas correntes; repasse de recursos, prestação de informações; orientações e capacitações de dirigentes de redes e escolas para execução e prestação de contas do programa; manutenção de dados cadastrais de unidades escolares. Fonte: Portal FNDE. 
Montantes e Gastos Anuais de Escolas Públicas com os Recursos do PDDE

\section{Metodologia}

Para a realização da parte empírica fez-se necessário uma revisão bibliográfica sobre o tema, enfocando a análise documental da legislação federal que fundamenta a descentralização dos recursos financeiros para as unidades escolares, a saber, o Programa Dinheiro Direto na Escola (PDDE) do Fundo Nacional de Desenvolvimento da Educação (FNDE), a fim de compreender os valores dos montantes repassados pelo PDDE, às duas escolas públicas selecionadas para a pesquisa. Em seguida foi realizado um levantamento de dados junto às escolas.

Com o intuito de levantar esses dados, fez-se necessário a aplicação de instrumentos distintos que foram capazes de sintetizar os dados que cada escola forneceu sobre os montantes repassados pelo PDDE e os destinos de suas despesas realizadas em cada ano. Os dados coletados foram encontrados em notas fiscais, documentos de prestação de contas, extratos bancários, balancetes escolares, entre outros.

O instrumento 1 foi retirado do relatório da pesquisa: Gestão financeira escolar como política pública: aplicação de instrumentos para levantamento de procedimentos legais e administrativos, processos participativos e montantes dos recursos financeiros destinados às escolas de redes públicas (VIANA, 2009; CAMARGO, 2012), e utilizado para contemplar as informações levantadas em campo, que foram agrupadas pelos anos definidos da pesquisa com dados relativos ao montante recebido pela escola, diferenciado em verba de custeio e verba de capital; o total do montante aplicado pela escola; o destino das despesas através da classificação das aplicações feitas em algumas categorias: material de consumo, material permanente, serviços de terceiros, impostos e taxas e outras despesas; e a quantidade de repasses do PDDE recebidos durante o período estipulado. Desse modo, as informações ficam mais claras para potencializar as análises dos dados. Conforme a estrutura demonstrada no Quadro 01.

\section{Quadro 01 - Estrutura da informação financeira dos recursos do PDDE destinados à Escola A e Escola B}

\begin{tabular}{|c|c|c|c|c|c|c|c|c|c|}
\hline \multirow{4}{*}{ Ano } & $\begin{array}{c}\text { Montante repassado / } \\
\text { ano } \\
\text { (RS) }\end{array}$ & \multicolumn{9}{|c|}{ Verba de Custeio } & $\begin{array}{c}\text { Verba de } \\
\text { Capital }\end{array}$ & Quantidade \\
\cline { 2 - 8 } & $\begin{array}{c}\text { Total do Montante } \\
\text { aplicado/ano (RS) }\end{array}$ & $\begin{array}{c}\text { Material de } \\
\text { Consumo (RS) }\end{array}$ & $\begin{array}{c}\text { Serviços de } \\
\text { terceiros (RS) }\end{array}$ & $\begin{array}{c}\text { Tarifas, taxas, } \\
\text { etc (RS) }\end{array}$ & $\begin{array}{c}\text { Transporte } \\
\text { (RS) }\end{array}$ & $\begin{array}{c}\text { Formação } \\
\text { Profissional (RS) }\end{array}$ & Outros (RS) & $\begin{array}{c}\text { Material } \\
\text { Permanente } \\
\text { (RS) }\end{array}$ & $\begin{array}{c}\text { no periodo } \\
\text { (Rsses }\end{array}$ \\
\hline
\end{tabular}

Fonte: Viana (2009; 2010; 2015) e Camargo (2012).

O instrumento 2 foi elaborado para permitir uma melhor organização e visualização das informações levantadas em campo com dados sobre cada período pesquisado (ano), a quantidade de alunos, o valor montante e o valor do repasse destinado a custeio e capital, o quanto esses montantes correspondem para cada aluno durante $\mathrm{o}$ ano pesquisado e 0 número de repasses. Conforme a estrutura apresentada no Quadro 02.

\section{Quadro 02 - Estrutura de informação financeira do PDDE referente ao custo aluno/ano}

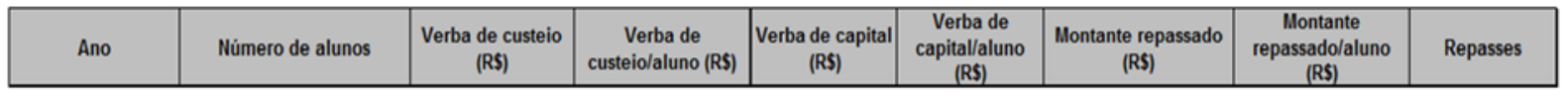

Fonte: Viana (2009; 2010; 2015) e Camargo (2012). 
O instrumento 3 foi elaborado a partir da Resolução FNDE (Fundo Nacional de Desenvolvimento da Educação) no 10, de 18 de abril de 2013, que estabelece uma nova base de cálculo para o PDDE, com o valor fixo de $\mathrm{R} \$ 1.000,00$ e o valor per capita por aluno/ano com valor de $\mathrm{R} \$ 20,00$. Esse valor per capita é definido pela quantidade de alunos declarada pela escola no Censo Escolar do ano anterior ${ }^{2}$. No Quadro 03 é possível observar o que foi previsto na legislação, com base no cálculo mencionado e o que de fato as escolas receberam. O valor per capita recebido foi calculado através da divisão do valor total recebido pelo número de alunos.

Quadro 03 - Forma de cálculo dos repasses do PDDE

\begin{tabular}{|c|c|c|c|c|c|c|}
\hline Ano & valor planejado & valor recebido & $\begin{array}{c}\text { Número de } \\
\text { alunos no ano } \\
\text { anterior }\end{array}$ & Valor fixo & $\begin{array}{c}\text { Valor per capita } \\
\text { planejado }\end{array}$ & $\begin{array}{c}\text { Valor per capita } \\
\text { recebido }\end{array}$ \\
\hline
\end{tabular}

Fonte: Elaborado pelos autores com base na Resolução FNDE n 10, de 18 e abril de 2013.

O período escolhido para a série histórica na escola Municipal (Escola A) foi de 2007 até 2016 e, na escola Estadual (Escola B), de 2006 a 2016, pois referem-se a uma continuidade da série histórica de pesquisa anteriormente realizada (CAMARGO, 2012) que contemplou o período de 2007 e 2008.

A escolha das escolas ocorreu mediante os seguintes critérios:

- Ter a direção da escola (ou a pessoa responsável pela aplicação dos recursos financeiros e demais recursos que chegam à escola) disponibilidade para a obtenção dos dados requeridos pela pesquisa;

- Ter Conselho de Escola e/ou APM no qual se delibere sobre a aplicação dos recursos financeiros;

- Não oferecer resistência à pesquisa, possibilitando o acesso a todas as fontes de documentação.

\section{Resultados e Discussão}

Este trabalho buscou descrever e analisar o PDDE a partir de sua criação até as reformulações mais atuais, que contemplam dez modalidades, também conhecidas como "ações agregadas ou complementares". Essas ações representam parcelas adicionais de recursos com propósitos específicos, que podem ser de natureza continuada ou não (MAFASSIOLI, 2017), além do PDDE (reconhecido como universal), também chamado de "PDDE Básico".

Buscou-se realizar uma síntese sobre o que é o programa a partir do seu aparato legal e literatura sobre esse tema. Em seguida, a fim de demonstrar de fato como acontece o recebimento e aplicação do programa, o trabalho divide-se em duas partes para demonstrar como o programa funciona nas duas escolas: a Escola A (da esfera municipal) e a Escola B (da rede estadual).

2 O valor total a ser repassado para cada escola é calculado levando em consideração o número de alunos matriculados na unidade educacional, extraído do Censo Escolar realizado pelo Inep/MEC do ano anterior ao do repasse. Fonte: Portal FNDE. 
Montantes e Gastos Anuais de Escolas Públicas com os Recursos do PDDE

\section{O que é PDDE?}

A iniciativa adotada pelo Ministério da Educação (MEC) para fomentar o processo de descentralização de recursos financeiros às escolas, implantado em 1995, foi a criação do Programa de Manutenção e Desenvolvimento do Ensino Fundamental (PMDE), com denominação alterada para Programa Dinheiro Direto na Escola (PDDE), pela Medida Provisória no 1.784, de 14 de dezembro de 1998, reafirmado pela Medida Provisória no 2.10032 , de 24 de maio de 2001 e ampliado pela Lei 11.947, de 16 de junho de 2009, que estendeu o programa para toda educação básica, passando a não ser recebido apenas por escolas de Ensino Fundamental.

Segundo a Resolução no 10 de 18 de abril de 2013, o PDDE é um programa por meio do qual o Fundo Nacional de Desenvolvimento da Educação (FNDE) repassa recursos em caráter suplementar para custeio e manutenção das atividades das escolas públicas de educação básica de ensino regular e especial, das redes municipais, estaduais e do Distrito Federal; das instituições privadas de educação especial, mantidas por entidades sem fins lucrativos e cadastradas no Conselho Nacional de Assistência Social; e a polos presenciais do sistema Universidade Aberta do Brasil (UAB), que oferecem programas de formação inicial ou continuada a profissionais da educação básica.

Desde a sua origem, conforme a Resolução n. 12, de 10 de maio de 1995 do FNDE (BRASIL, 1995), justifica-se a transferência de recursos financeiros paras as unidades escolares pela necessidade de adotar-se medidas racionalizadoras, menos burocráticas, de modo que os recursos cheguem com mais agilidade e diretamente às escolas.

O programa passou por uma série de transformações, mas sempre teve como objetivo: suplementar às escolas com recursos financeiros, visando à melhoria da infraestrutura física e pedagógica das instituições, sem intermediários; incentivar a autonomia gerencial, a participação da comunidade escolar e o atendimento das necessidades locais.

As escolas públicas beneficiárias do PDDE são entidades com personalidade jurídica incapazes de reunir os elementos exigidos pelo Banco Central para possuir, em nome próprio, a conta bancária na qual serão depositados os recursos. Por isso, o FNDE encontrou como alternativa técnica criar a figura da Unidade Executora (UEx) ${ }^{3}$.

A verba do PDDE é destinada diretamente às escolas, independente de sua localidade rural ou urbana, e é proporcional ao número de alunos matriculados, podendo ser aplicada na aquisição de materiais permanentes, materiais de uso diário, na realização de pequenos reparos na infraestrutura física dos prédios, na contratação de mão de obra, em materiais para a implementação do Projeto Político-Pedagógico (PPP), em instrumentos que permitem avaliar a aprendizagem e para o desenvolvimento de atividades educacionais em geral.

3 Unidade Executora Própria (UEx) é uma entidade privada sem fins lucrativos, representativa das escolas públicas e dos polos presenciais da UAB, integrada por membros das comunidades escolar e local, comumente denominada de caixa escolar, associação de pais e mestres, conselho escolar, círculo de pais e mestres, etc., responsáveis pela formalização dos procedimentos necessários ao recebimento, execução e prestação de contas dos recursos destinados às referidas escolas e polos. Fonte: FNDE. Disponível em $<$ http://cursos.fnde.gov.br/mdl07/pdf/ParteinicialdoCurso.pdf>. Manual PDDE de 2013. Acesso em: 19 set. 2018. 
Segundo Viana (2015), uma alteração legal importante foi que as escolas passaram a poder definir os percentuais a serem repassados para gastos com custeio ou capital ${ }^{4}$, podendo priorizar suas necessidades por categoria econômica, conforme suas necessidades. De acordo com a Resolução n 10/2013, Artigo 11:

As Unidades Executoras (UEx), representativas de escolas públicas e de polos presenciais da Universidade Aberta do Brasil (UAB), e as Entidades Mantenedoras (EM), representativas de escolas privadas de educação especial, deverão informar ao FNDE, até o dia 31 de dezembro de cada exercício, por intermédio do sistema PDDEWeb, os percentuais de recursos que desejarão receber em custeio e/ou capital no exercício subsequente ao da informação. Em caso de não adoção da iniciativa referida no parágrafo anterior, são destinados às escolas $80 \%$ (oitenta por cento) em recursos de custeio e $20 \%$ (vinte por cento) em recursos de capital (VIANA, 2015, p. 151).

O volume de recursos do PDDE passou, em valores nominais, de pouco mais de R\$ 229,3 milhões no ano de 1995, para mais de R\$1,5 bilhão em 2015, e teve o seu ápice de transferência em 2013, quando alcançou a quantia de R\$2,6 bilhões (BRASIL, 2018).

$\mathrm{Na}$ tabela a seguir é possível encontrar quais os valores referenciais de cálculo para repasses do PDDE, segundo a Resolução FNDE n 10, de 18 de abril de 2013:

Tabela 1 - Valor Fixo e valor por aluno do PDDE para cada escola do país

\begin{tabular}{|l|c|c|}
\hline Especificação & Valor Fixo (R\$) & $\begin{array}{c}\text { Valor per capita } \\
(\mathrm{R} \$)\end{array}$ \\
\hline Escola pública urbana com UEx & $1.000,00$ & 20,00 \\
\hline Escola pública rural com UEx & $2.000,00$ & 20,00 \\
\hline Escola privada de educação especial & $1.000,00$ & 60,00 \\
\hline Escola pública urbana sem UEx & - & 40,00 \\
\hline Escola pública rural sem UEx & - & 60,00 \\
\hline Público alvo da educação especial em escola pública & - & 80,00 \\
\hline
\end{tabular}

Fonte: Elaborada pelos autores com base na Resolução FNDE no 10 de 18 de abril de 2013.

Sendo assim, pode-se estimar o valor do montante que as escolas deveriam receber a partir de 2013 segundo o cálculo: Valor total = Valor fixo + Valor variável (Número de alunos $\mathrm{x}$ valor per capita).

Por exemplo: Numa escola pública urbana com UEx e 500 alunos matriculados, o valor seria: Um valor fixo $+500 \times$ valor per capita, ou seja, o valor total seria $R \$ 1.000,00+(500$ matrículas $x \mathrm{R} \$ 20,00)=R \$ 11.000,00$.

Conforme Mafassioli (2017), o PDDE é um dos programas de assistência financeira mais longevos do MEC, somente o Programa Nacional de Alimentação Escolar (PNAE) é mais antigo. Em volume de recursos, é a quarta transferência (está atrás da complementação da União ao FUNDEB, da repartição da receita do salário educação com estados e municípios e da merenda escolar). A autora também sistematizou o formato de classificação com o qual o FNDE trabalha esses recursos, que são agrupados pelos seguintes eixos estruturantes:

A parcela dos recursos do PDDE que pertence à categoria de custeio destina-se a cobrir despesas relacionadas à aquisição de material de consumo (materiais de expediente, limpeza, construção, etc.) e contratação de serviços (manutenção hidráulica, elétrica, jardinagem etc.). Já a parcela de capital deve ser empregada na aquisição de materiais permanentes (eletrodomésticos, computadores, mobiliário, etc.). Fonte: Portal FNDE. 
- PDDE Básico (universal): destina-se à manutenção do ambiente escolar e à aquisição de materiais que eram recebidos por todas as escolas públicas brasileiras, e foi, até 2003, o único formato de transferência para as instituições de ensino alvo do Programa. - PDDE Qualidade: voltado ao atendimento das necessidades pedagógicas da escola. Este eixo inclui o PDDE - PDE, o PDDE - Escola Aberta, o PDDE - Ensino Médio Inovador, o PDDE - Atletas na Escola, o PDDE - Sustentável e o PDDE - Mais Cultura. - PDDE Integral: direcionado para promover a educação integral nas escolas públicas brasileiras a partir das ações do Programa Mais Educação.

- PDDE Estrutura: possui como foco a estrutura física da escola e inclui o PDDE Acessível, o PDDE - Água na Escola e o PDDE - Escola do Campo como os seus financiadores (MAFASSIOLI, 2015, p. 140).

Os recursos do PDDE não podem ser utilizados em gastos com pagamento de pessoal com ou sem vínculo empregatício; na compra de livros didáticos e de literatura já distribuídos pelo FNDE por meio do Programa Nacional do Livro Didático (PNLD) e do Programa Nacional Biblioteca da Escola (PNBE); em gêneros alimentícios contemplados pelo PNAE; aquisição de uniforme escolar; pagamento de passagens e diárias; pagamento de contas de água, luz, telefone e quaisquer outras taxas, tarifas bancárias e tributos federais, distritais, estaduais e municipais; em despesas com festas e comemorações. Também é vedado o uso do dinheiro para implementar ações que já são objeto de financiamento do FNDE e que já contam com o Programa Nacional de Apoio ao Transporte do Escolar (PNATE).

Conforme a Resolução FNDE n 05 de 31 de março de 2014, a quantidade de repasses do PDDE foi alterada, passando a ser duas parcelas anuais e, com a Resolução $n^{\circ} 6$, de 27 de fevereiro de 2018, os repasses dos recursos dar-se-ão em duas parcelas anuais, devendo o pagamento da primeira parcela ser efetivado até 30 de abril e, o da segunda parcela, até 30 de setembro de cada exercício à Entidade Executora $(\mathrm{EEx})^{5}$, Unidade Executora Própria (UEx) e Entidade Mantenedora (EM) ${ }^{6}$ que cumprirem as exigências de atualização cadastral até a data de efetivação dos pagamentos.

\section{Escola A}

A "Escola A" refere-se a uma escola da rede municipal de educação de São Paulo que atende o Ensino Fundamental I e II, além de ensino integral no ciclo de alfabetização, começando pelo $1^{\circ}$ ano do EF I em $2016,1^{\circ}$ e $2^{\circ}$ ano do EF I em 2017, sendo que o ciclo completo dos três anos iniciais do EF I tornou-se em tempo integral em 2018. O período histórico contemplado pela pesquisa é de 2007 a 2016. Com o objetivo de descrever melhor a série histórica, foi necessário apresentar duas tabelas (uma com valores nominais, outra

5 Prefeituras municipais e secretarias distritais e estaduais responsáveis pela formalização dos procedimentos necessários ao recebimento, execução e prestação de contas dos recursos do programa, destinados às escolas de suas redes de ensino que não possuem UEx. Fonte: FNDE. Disponível em <http://cursos.fnde.gov.br/mdl07/pdf/ParteinicialdoCurso.pdf>. Manual PDDE de 2013. Acesso em: 19 set. 2018.

6 Entidade privada sem fins lucrativos, qualificada como beneficente de assistência social, ou de atendimento direto e gratuito ao público, representativa das escolas privadas de educação especial, responsáveis pela formalização dos procedimentos necessários ao recebimento dos repasses do programa, bem como pela execução e prestação de contas desses recursos. Dirigentes de unidades executoras de escolas prestam contas referente ao uso dos recursos do PDDE. Estas contas passam por análise das respectivas secretarias de educação e a consolidação feita pelas secretarias passa por análise do FNDE. Caso a secretaria receba recursos referentes ao PDDE para escolas com menos de 50 alunos, fica responsável pela elaboração da prestação de contas. Fonte: FNDE. Disponível em <http://cursos.fnde.gov.br/mdl07/pdf/ParteinicialdoCurso.pdf> Manual PDDE de 2013. Acesso em: 19 set. 2018. 
com valores corrigidos) para possibilitar a visualização do número de alunos, o valor dos montantes referentes à verba de custeio e à verba capital e o valor repassado por aluno/ano e o montante repassado anualmente.

Tabela 2 - Montante dos recursos repassados pelo PDDE Básico ano/aluno - Valores Nominais (escola A)

\begin{tabular}{|c|c|c|c|c|c|c|c|c|}
\hline Ano & Número de alunos & $\begin{array}{c}\text { Verba de custeio } \\
\text { (RS) }\end{array}$ & \begin{tabular}{c|} 
Verba de \\
custeio/aluno (RS)
\end{tabular} & $\begin{array}{l}\text { Verba de } \\
\text { capital (RS) }\end{array}$ & $\begin{array}{c}\text { Verba de } \\
\text { capitalaluno } \\
\text { (RS) }\end{array}$ & $\begin{array}{c}\text { Montante repassado } \\
\text { (RS) }\end{array}$ & $\begin{array}{c}\text { Montante } \\
\text { repassado/aluno } \\
\text { (RS) }\end{array}$ & Repasses \\
\hline 2007 & 775 & $5.057,44$ & 6,53 & $1.264,36$ & 1,63 & $6.321,80$ & 8,16 & 1 \\
\hline 2008 & 727 & $6.078,38$ & 8,36 & $2.026,13$ & 2,79 & $8.104,51$ & 11,15 & 1 \\
\hline 2009 & 694 & $7.490,40$ & 10,79 & $1.872,60$ & 2,70 & $9.363,00$ & 13,49 & 1 \\
\hline 2010 & 635 & $4.097,28$ & 6,45 & $1.024,32$ & 1,61 & $5.121,60$ & 8,07 & 1 \\
\hline 2011 & 608 & $5.086,32$ & 8,37 & $5.068,68$ & 8,34 & $10.155,00$ & 16,70 & 1 \\
\hline 2012 & 554 & $2.969,64$ & 5,36 & $1.979,76$ & 3,57 & $4.949,40$ & 8,93 & 1 \\
\hline 2013 & 502 & $9.904,00$ & 19,73 & $2.476,00$ & 4,93 & $12.380,00$ & 24,66 & 1 \\
\hline 2014 & 512 & $4.416,00$ & 8,63 & $1.104,00$ & 2,16 & $5.520,00$ & 10,78 & 1 \\
\hline 2015 & 499 & $4.416,00$ & 8,85 & $1.104,00$ & 2,21 & $5.520,00$ & 11,06 & 1 \\
\hline 2016 & 468 & $13.384,00$ & 28,60 & $3.346,00$ & 7,15 & $16.730,00$ & 35,75 & 1 \\
\hline
\end{tabular}

Fonte: Elaborado pelos autores a partir dos dados levantados em campo.

Tabela 3 - Montante dos recursos repassados pelo PDDE Básico ano/aluno - valores monetários atualizados para dezembro de 2013 pelo Índice Nacional de Preços ao Consumidor (INPC), do IBGE

\begin{tabular}{|c|c|c|c|c|c|c|c|c|c|}
\hline Ano & $\begin{array}{c}\text { Quantidade } \\
\text { de alunos }\end{array}$ & $\begin{array}{c}\text { Verba de } \\
\text { Custeio (RS) }\end{array}$ & $\begin{array}{c}\text { Verba } \\
\text { custeio/aluno } \\
\text { (RS) }\end{array}$ & $\begin{array}{l}\text { Verba de } \\
\text { Capital (R\$) }\end{array}$ & $\begin{array}{c}\text { Verba de } \\
\text { capital/aluno } \\
\text { (RS) }\end{array}$ & $\begin{array}{l}\text { Total do } \\
\text { repasse }\end{array}$ & $\begin{array}{l}\text { Valor por } \\
\text { aluno }\end{array}$ & $\begin{array}{l}\text { Total de } \\
\text { Repasses }\end{array}$ & $\begin{array}{c}\text { Data do recebimento } \\
\text { do repasse pela escola } \\
\text { e data da correção do } \\
\text { valor }\end{array}$ \\
\hline 2007 & 775 & 9201,97 & 11,87 & 2300,49 & 2,97 & 11502,46 & 14,84 & 1 & $07 / 2007$ a $12 / 2016$ \\
\hline 2008 & 727 & 10309,20 & 14,18 & 3436,41 & 4,73 & 13745,61 & 18,91 & 1 & $07 / 2008$ a $12 / 2016$ \\
\hline 2009 & 694 & 12106,39 & 17,44 & 3026,60 & 4,36 & 15132,99 & 21,81 & 1 & $07 / 2009$ a $12 / 2016$ \\
\hline 2010 & 635 & 6239,08 & 9,83 & 1536,95 & 2,42 & 7776,03 & 12,25 & 1 & $11 / 2010$ a $12 / 2016$ \\
\hline 2011 & 608 & 7284,71 & 11,98 & 7605,34 & 12,51 & 14890,05 & 24,49 & 1 & $10 / 2011$ a $12 / 2016$ \\
\hline 2012 & 554 & 4122,84 & 7,44 & 2748,56 & 4,96 & 6871,40 & 12,40 & 1 & $05 / 2012$ a $12 / 2016$ \\
\hline 2013 & 502 & 12830,88 & 25,56 & 3207,72 & 6,39 & 16035,60 & 31,94 & 1 & $05 / 2013$ a $12 / 2016$ \\
\hline 2014 & 512 & 5406,64 & 10,56 & 1351,66 & 2,64 & 6758,30 & 13,20 & 1 & $05 / 2014$ a $12 / 2016$ \\
\hline 2015 & 499 & 5160,91 & 10,34 & 1290,23 & 2,59 & 6451,14 & 12,93 & 1 & $02 / 2015$ a $12 / 2016$ \\
\hline 2016 & 468 & 13771,11 & 29,43 & 3442,78 & 7,36 & 17213,89 & 36,78 & 1 & $05 / 2016$ a $12 / 2016$ \\
\hline
\end{tabular}

Fonte: Elaborado pelos autores a partir dos dados levantados em campo.

É possível perceber na Tabela 2 que, durante todos os anos pesquisados, a Escola A recebeu apenas um repasse do PDDE, mesmo após 2013, quando a legislação do programa possibilitou mais de um repasse anual. Os anos em que a escola recebeu os maiores montantes nominais foram 2011, 2013 e 2016, porém na Tabela 2 os valores foram corrigidos e os maiores montantes recebidos foram nos anos 2009, 2013 e 2016.

As datas do recebimento do repasse do PDDE pela escola variaram entre fevereiro, no ano de 2010, a novembro, no ano de 2015, porém na maioria dos anos a escola recebeu o recurso do PDDE em maio. Esse dado mostra-se importante, pois, para o planejamento financeiro da escola é necessário que os repasses sejam recebidos em meses estipulados, pois assim o cronograma previsto por ela poderá ser cumprido.

O valor/aluno do repasse do PDDE destinado à verba de custeio é significativamente maior do que à verba de capital, com exceção do ano de 2011, em que ambas as verbas por aluno ano foram aproximadas ( $R \$ 8,37$ para custeio e $R \$ 8,34$ para capital em valores nominais) em valores corrigidos até a data final da pesquisa $R \$ 11,98$ e $R \$ 12,51$ respectivamente.

Nos anos de 2014 e de 2015, os montantes de recursos recebidos pelo PDDE tiveram o mesmo valor nominal, porém, quando corrigidos os valores pelos índices da inflação o valor do ano de 2015 foi menor. O ano em que a Escola A recebeu mais recursos do PDDE foi o ano de 2016. 
As despesas da Escola $\mathrm{A}$ foram organizadas na Tabela 4 a fim de obter uma melhor visualização do total repassado e aplicado pela escola na aquisição de material de consumo (atribuído a verba de custeio) e material permanente (atribuído a verba de capital), bem como a quantidade de repasses recebidos no período compreendido. O destino das despesas foi classificado pelas seguintes categorias: material de consumo, material permanente, serviços de terceiros, impostos e taxas, transporte, formação profissional e outros; com o intuito de possibilitar uma melhor compreensão sobre os gastos.

\section{Tabela 4 - Destino dos recursos repassados pelo programa PDDE Básico à Escola A de 2007 a} 2016 - valores nominais

\begin{tabular}{|c|c|c|c|c|c|c|c|c|c|}
\hline \multirow{2}{*}{ Ano } & $\begin{array}{c}\text { Montante repassado / } \\
\text { ano }\end{array}$ & \multicolumn{6}{|c|}{ Verba de Custeio } & \multirow{2}{*}{$\begin{array}{c}\begin{array}{c}\text { Verba de } \\
\text { Capital }\end{array} \\
\begin{array}{c}\text { Material } \\
\text { Permanente } \\
\text { (RS) }\end{array}\end{array}$} & \multirow{2}{*}{$\begin{array}{l}\text { Quantidade } \\
\text { de Repasses } \\
\text { no periodo }\end{array}$} \\
\hline & $\begin{array}{l}\text { Total do Montante } \\
\text { aplicado/ano (RS) }\end{array}$ & $\begin{array}{c}\text { Material de } \\
\text { Consumo (RS) }\end{array}$ & $\begin{array}{l}\text { Serviços de } \\
\text { terceiros (RS) }\end{array}$ & $\begin{array}{l}\text { Tarifas, taxas, } \\
\text { etc (RS) }\end{array}$ & $\begin{array}{c}\text { Transporte } \\
\text { (RS) }\end{array}$ & $\begin{array}{c}\text { Formação } \\
\text { Profissional (RS) }\end{array}$ & Outros (RS) & & \\
\hline \multirow{2}{*}{2007} & $6.321,80$ & $5.057,44$ & & & & & & $1.264,36$ & \multirow{2}{*}{1} \\
\hline & $6.481,89$ & $3.501,93$ & $1.376,00$ & 23,51 & & & & $1.580,45$ & \\
\hline \multirow{2}{*}{2008} & $8.104,51$ & $6.078,38$ & & & & & & $2.026,13$ & \multirow{2}{*}{1} \\
\hline & $3.915,65$ & $1.319,43$ & 399,84 & 76,16 & & & & $2.120,22$ & \\
\hline \multirow{2}{*}{2009} & $9.363,00$ & $7,490,40$ & & & & & & $9.363,00$ & \multirow{2}{*}{1} \\
\hline & 7490,40 & $7.490,40$ & & & & & & $1.872,60$ & \\
\hline \multirow{2}{*}{2010} & $5.121,60$ & $4.097,28$ & & & & & & $1.024,32$ & \multirow{2}{*}{1} \\
\hline & $5.964,29$ & $4,048,17$ & & & & & & $1.916,12$ & \\
\hline \multirow{2}{*}{2011} & $10.155,00$ & $5.086,32$ & & & & & & $5.068,68$ & \multirow{2}{*}{1} \\
\hline & $8.301,76$ & $5.322,76$ & & & & & & $2.979,00$ & \\
\hline \multirow{2}{*}{2012} & 4949,40 & $2.969,64$ & & & & & & $1.979,76$ & \multirow{2}{*}{1} \\
\hline & $5.007,73$ & $3.004,87$ & & & & & & $2.202,86$ & \\
\hline \multirow{2}{*}{2013} & $12.380,00$ & $9.904,00$ & & & & & & $2.476,00$ & \multirow{2}{*}{1} \\
\hline & $12.429,83$ & $6.063,14$ & $3.880,00$ & & & & & $2.486,69$ & \\
\hline \multirow{2}{*}{2014} & $5.520,00$ & $4.416,00$ & & & & & & $1.104,00$ & \multirow{2}{*}{1} \\
\hline & $5.997,09$ & $4.477,09$ & & & & & & $1.520,00$ & \\
\hline \multirow{2}{*}{2015} & $5.520,00$ & $4,416,00$ & & & & & & $1.104,00$ & \multirow{2}{*}{1} \\
\hline & $5.674,06$ & $4.539,25$ & & & & & & $1.134,81$ & \\
\hline \multirow{2}{*}{2016} & $16.730,00$ & $13.384,00$ & & & & & & $3.346,00$ & \multirow{2}{*}{1} \\
\hline & $12.889,16$ & $4.939,16$ & $3.265,00$ & & 525,00 & & & $4.160,00$ & \\
\hline
\end{tabular}

Fonte: Elaborado pelos autores a partir dos dados levantados em campo e instrumento de Viana (2010).

Com base na Tabela 4 podemos perceber que, nos anos 2007, 2010, 2012, 2013, 2014 e 2015, a escola gastou mais do que o montante recebido pelo PDDE, pois contava com uma reserva em caixa, provavelmente de anos anteriores. Entretanto, nos anos de 2008, 2009, 2011 e 2016 a escola gastou um montante menor do que o montante recebido pelo PDDE no mesmo ano.

Em todos os anos o PDDE foi usado para custear material de consumo. O pagamento para serviços de terceiros foi utilizado apenas nos anos 2007, 2008, 2013 e 2016. Apenas durante o ano de 2007 e 2008 foram usados recursos do PDDE para pagamento de tarifas bancárias e taxas. Apenas em 2016 a escola A usou o PDDE para locação de transporte. Em 2015 e 2016 a escola utilizou a verba de custeio para adquirir material para jardinagem; em 2008 e 2013 com a verba de custeio adquiriu-se materiais esportivos para escola.

Em relação aos serviços de terceiros que a escola contratou, no ano de 2007 a escola custeou reparos em cadeiras e manutenção de máquinas e equipamento; em 2008 foi realizada a instalação de fiação nova na cozinha, refeitório e dispensa; em 2013 foi realizado serviços de alvenaria e de manutenção do telhado; em 2016 foram contratados serviços de pintura e de instalação do sinalizador musical. 
Apenas nos anos de 2011, 2014 e 2015 não foram usados os recursos do PDDE para comprar material de manutenção. Em todos os anos a Escola A utilizou recursos do PDDE para arcar com os custos de materiais didáticos/pedagógicos e em nenhum ano contemplado pela pesquisa a escola utilizou os recursos do PDDE para a formação profissional.

Segundo a Resolução FNDE n 10, de 18 de abril de 2013, o valor a ser recebido nas escolas urbanas, como é o caso dessa instituição de ensino, deveria ser de $\mathrm{R} \$ 20,00$ per capita mais a parte fixa de $R \$ 1.000,00$, porém a tabela 5 demonstra que essa resolução não foi contemplada na Escola A, uma vez que, em 2014 e 2015, recebeu o valor per capita menor do que o planejado. No entanto, em 2016, embora o número de matriculados tenha sido o menor da série histórica analisada, o valor recebido foi superior aos demais. Cabe destacar que, em 2016, o primeiro ano do Ensino Fundamental I desta escola tornou-se integral e, neste caso, o valor per capita do aluno em tempo integral é o dobro, porém, como o cálculo é feito com base no Censo Escolar do ano anterior, em 2016 a escola recebeu o montante do PDDE referente aos alunos matriculados em 2015, que não era integral.

Tabela 5 - Valor planejado e recebido pela Escola A a partir da Resolução FNDE n 10/ 2013 valores nominais $(\mathbf{R} \$)$

\begin{tabular}{|c|c|c|c|c|c|c|}
\hline Ano & valor planejado & valor recebido & $\begin{array}{c}\text { Número de } \\
\text { alunos no ano } \\
\text { anterior }\end{array}$ & Valor fixo & $\begin{array}{c}\text { Valor per capita } \\
\text { planejado }\end{array}$ & $\begin{array}{c}\text { Valor per capita } \\
\text { recebido }\end{array}$ \\
\hline $\mathbf{2 0 1 3}$ & $12.080,00$ & $12.380,00$ & 554 & $1.000,00$ & 20 & 20,54 \\
\hline $\mathbf{2 0 1 4}$ & $11.040,00$ & $5.520,00$ & 502 & $1.000,00$ & 20 & 9,00 \\
\hline $\mathbf{2 0 1 5}$ & $11.240,00$ & $5.520,00$ & 512 & $1.000,00$ & 20 & 8,83 \\
\hline $\mathbf{2 0 1 6}$ & $10.980,00$ & $16.730,00$ & 499 & $1.000,00$ & 20 & 31,52 \\
\hline
\end{tabular}

Fonte: Elaborados pelos autores com dados levantados em campo.

Finalizando, o valor recebido por aluno pela Escola A por meio do PDDE foi maior do que o valor planejado $(R \$ 20,00)$ nos anos de 2013 e 2016, pois os valores recebidos foram de $R \$ 20,54$ e $R \$ 31,52$, respectivamente. Como era de se esperar, pois deve ser somada a parte fixa, no entanto, nos anos de 2014 e 2015 os valores recebidos por aluno foram bem menores ao estipulado pela resolução do FNDE citada anteriormente, pois foram somente R\$ 8,83 e $\mathrm{R} \$ 9,00$ per capita.

\section{Escola $B$}

A Escola B está jurisdicionada na rede estadual de ensino de São Paulo o período histórico que a pesquisa abrange, diferentemente da Escola A, foram os anos de 2006 a 2016, pela disponibilidade da escola. Para analisar melhor a série histórica foi necessário organizar os valores obtidos na escola para uma tabela que permitiu visualizar com mais clareza o quanto a escola recebeu, o destino desse valor e quantos foram os repasses em cada ano.

Para uma análise sobre o montante dos recursos repassados pelo programa PDDE para a Escola B, fez-se necessário a criação de duas tabelas (uma com valores nominais, outra com valores corrigidos) em que foi possível visualizar o número de alunos, o valor dos montantes referentes à verba de custeio e a verba capital e o valor repassado por aluno/ano e o montante repassado anualmente. As tabelas mencionadas encontram-se abaixo: 
Montantes e Gastos Anuais de Escolas Públicas com os Recursos do PDDE

Tabela 6 - Montante dos recursos repassados pelo programa PDDE Básico ano/aluno para a Escola B (valores em $\mathbf{R} \$$ nominais)

\begin{tabular}{|c|c|c|c|c|c|c|c|c|}
\hline Ano & $\begin{array}{c}\text { Número } \\
\text { de alunos }\end{array}$ & $\begin{array}{c}\text { Verba de } \\
\text { custeio } \\
\text { (RS) }\end{array}$ & $\begin{array}{c}\text { Verba de } \\
\text { custeio/alun } \\
\text { o (RS) }\end{array}$ & $\begin{array}{c}\text { Verba de } \\
\text { capital (RS) }\end{array}$ & $\begin{array}{c}\text { Verba de } \\
\text { capital/aluno } \\
\text { (RS) }\end{array}$ & $\begin{array}{c}\text { Montante } \\
\text { repassado } \\
\text { (RS) }\end{array}$ & $\begin{array}{c}\text { Montante } \\
\text { repassado/alun } \\
\text { o } \\
\text { (RS) }\end{array}$ & $\begin{array}{c}\text { Repas } \\
\text { ses }\end{array}$ \\
\hline $\mathbf{2 0 0 6}$ & 715 & $4.356,00$ & 6,09 & $1.089,00$ & 1,52 & $5.445,00$ & 7,62 & 1 \\
\hline $\mathbf{2 0 0 7}$ & 700 & $4.356,20$ & 6,22 & $1.089,00$ & 1,56 & $5.445,20$ & 7,78 & 1 \\
\hline $\mathbf{2 0 0 8}$ & 670 & $4.288,80$ & 6,40 & $1.072,20$ & 1,60 & $5.361,00$ & 8,00 & 1 \\
\hline $\mathbf{2 0 0 9}$ & 658 & $3.664,50$ & 5,57 & $1.570,50$ & 2,39 & $5.235,00$ & 7,96 & 1 \\
\hline $\mathbf{2 0 1 0}$ & 654 & $2.078,88$ & 3,18 & $3.129,60$ & 4,79 & $5.208,48$ & 7,96 & 1 \\
\hline $\mathbf{2 0 1 1}$ & 640 & $4.175,56$ & 6,52 & $6.262,52$ & 9,79 & $10.438,08$ & 16,31 & 2 \\
\hline $\mathbf{2 0 1 2}$ & 665 & $3.067,92$ & 4,61 & $4.601,88$ & 6,92 & $7.669,80$ & 11,53 & 1 \\
\hline $\mathbf{2 0 1 3}$ & 662 & $7.503,69$ & 11,33 & $7.503,69$ & 11,33 & $15.007,38$ & 22,67 & 1 \\
\hline $\mathbf{2 0 1 4}$ & 630 & $2.650,00$ & 4,21 & $6.428,15$ & 10,20 & $9.078,15$ & 14,41 & 1 \\
\hline $\mathbf{2 0 1 5}$ & 640 & $2.665,21$ & 4,16 & $5.532,29$ & 8,64 & $8.197,50$ & 12,81 & 1 \\
\hline $\mathbf{2 0 1 6}$ & 620 & $22.575,36$ & 36,41 & $5.532,00$ & 8,92 & $28.107,36$ & 45,33 & 3 \\
\hline
\end{tabular}

Fonte: Elaborado pelos autores a partir dos dados levantados em campo.

Tabela 7 - Montante dos recursos repassados pelo programa PDDE Básico no ano/ aluno para a Escola B em R \$ corrigidos pela INPC (IBGE) de Dezembro de 2016

\begin{tabular}{|c|c|c|c|c|c|c|c|c|}
\hline Ano & $\begin{array}{c}\text { Número } \\
\text { de } \\
\text { alunos }\end{array}$ & $\begin{array}{c}\text { Verba de } \\
\text { custeio } \\
\text { (RS) }\end{array}$ & $\begin{array}{c}\text { Verba de } \\
\text { custeio/alun } \\
\text { o(RS) }\end{array}$ & $\begin{array}{c}\text { Verba de } \\
\text { capital (RS) }\end{array}$ & $\begin{array}{l}\text { Verba de } \\
\text { capitaV/al } \\
\text { uno (RS) }\end{array}$ & $\begin{array}{c}\text { Montante } \\
\text { repassado } \\
\text { (RS) }\end{array}$ & $\begin{array}{c}\text { Montante } \\
\text { repassado/ } \\
\text { aluno } \\
\text { (RS) }\end{array}$ & $\begin{array}{c}\text { Repasse } \\
\text { s }\end{array}$ \\
\hline 2006 & 715 & $8.150,26$ & 11,40 & $2.037,57$ & 2,85 & 10.187 .83 & 14,25 & 1 \\
\hline 2007 & 700 & 7.777 .98 & 11,11 & 1944,40 & 2,78 & $9.722,38$ & 13,89 & 1 \\
\hline 2008 & 670 & $7.143,09$ & 10,66 & $1.785,77$ & 2,67 & $8.928,86$ & 13,33 & 1 \\
\hline 2009 & 658 & 5.859 .22 & 8,90 & $2.511,10$ & 3,82 & 8370,32 & 12,72 & 1 \\
\hline 2010 & 654 & $3.133,32$ & 4,79 & $4.716,97$ & 7,21 & $7.850,29$ & 12,00 & 1 \\
\hline 2011 & 640 & 5927,45 & 9,26 & $8.890,00$ & 13,89 & $14.817,45$ & 23,15 & 2 \\
\hline 2012 & 665 & $4.110,31$ & 6,18 & $6.165,45$ & 9.27 & $10.275,76$ & 15,45 & 1 \\
\hline 2013 & 662 & 9.521 .57 & 14,38 & $9.521,56$ & 14,38 & $19.043,13$ & 28,77 & 1 \\
\hline 2014 & 630 & $3.162,34$ & 5,02 & $7.670,93$ & 12,18 & $10.833,27$ & 17,20 & 1 \\
\hline 2015 & 640 & $2.866,14$ & 4,48 & 5949,38 & 2,08 & $8.815,52$ & 13,77 & 1 \\
\hline 2016 & 620 & $22.575,36$ & 36,41 & $5.532,00$ & 8,92 & $28.107,36$ & 45,33 & 3 \\
\hline
\end{tabular}

Fonte: Elaborado pelos autores a partir dos dados levantados em campo.

A partir das tabelas acima, foi possível verificar que até o ano de 2012 houve uma queda em relação no número de alunos da escola. Em 2006, a escola possuía 715 alunos e, em 2011, esse número chegou a 640. Nos anos de 2012 e 2013, o número de alunos sobe para cerca de 660 alunos, mas cai para 630 em 2014. O número aumenta para 640 em 2015 e, em 2016, chega a 620.

Com base na tabela 6, em valores nominais durante os anos de 2006 até o ano de 2010 a escola recebeu aproximadamente a mesma quantia (cerca de $\mathrm{R} \$ 5.300$ por ano em média), no ano de 2011 houve um aumento desse valor para quase o dobro, com dois repasses. Com isso, os próximos valores recebidos aumentam e são bem mais altos nos anos de 2013 e 2016.

Observa-se também que, após o ano de 2010, a escola recebeu um valor de verba de capital superior ao valor de verba de custeio e somente no ano de 2013 o montante da verba de capital foi igual ao da verba de custeio. Assim, é possível observar que, até o ano de 2009, o valor recebido por aluno é maior em verba de custeio do que verba de capital e que a partir do ano 2010 isso se inverte. 
Com base na tabela 7, é possível observar que o ano no qual se registrou o maior valor por aluno recebido pelo PDDE foi em 2016 ( $R \$ 45,33)$, seguido pelos anos de 2013 (R\$28,77) e 2011 ( $R \$ 23,15)$; já o menor valor registrado foi no ano de 2010 ( $R \$ 12,00)$. Na mesma tabela, em valores corrigidos, percebe-se que o primeiro ano de registro dos montantes repassados pelo PDDE é o ano de 2006. Neste ano a escola recebeu por aluno $R \$ 14,25$, o que representa $31,4 \%$ do maior valor recebido ( $R \$ 45,33)$. Como 2016 também é o ano no qual a escola registrou o menor número de alunos, pode ter ampliado o valor per capita.

No entanto, mesmo que a escola tivesse no ano de 2016 a mesma quantidade de alunos do que no ano de 2006, ou seja, 715 alunos, o valor teria sido de $\mathrm{R} \$ 39,30$ e ainda assim seria o maior valor recebido durante o período pela escola.

Para uma análise sobre o destino dos recursos repassados para a Escola $B$, fez-se necessário a elaboração de uma tabela em que fosse possível identificar os valores recebidos pela escola em cada ano e os tipos de gastos que a escola realizou em cada ano e assim poder comparar os anos entre si.

A tabela 8 está dividida em: ano dos repasses, montante repassado por ano (que se refere ao valor total recebido pela escola referente ao PDDE); verba de custeio (destina-se a cobrir despesas a aquisição de material de consumo, ou seja, materiais de limpeza de construção, material expediente, serviços de terceiros, tarifas, taxas etc., transporte e formação profissional); verba de capital, que deve ser usada para compra de materiais permanentes (materiais que são patrimoniados); e, por fim, número de repasses no ano.

Tabela 8 - Destino dos Recursos Repassados Pelo PDDE Básico (Escola B) - valores em R\$ nominais

\begin{tabular}{|c|c|c|c|c|c|c|c|c|c|}
\hline \multirow{2}{*}{ Ano } & \begin{tabular}{|c|} 
Montante \\
repassado / \\
ano
\end{tabular} & \multicolumn{6}{|c|}{ Verba de Custeio } & Verba de & \multirow{4}{*}{$\begin{array}{c}\text { Quantidade de } \\
\text { Repasses no } \\
\text { periodo }\end{array}$} \\
\hline & $5.445,00$ & & & & $4.356,00$ & & & $1.089,00$ & \\
\hline \multirow[t]{2}{*}{2006} & \begin{tabular}{|c|} 
Total do \\
Montante \\
aplicado/ano \\
(RS)
\end{tabular} & $\begin{array}{c}\text { Material de } \\
\text { Consumo } \\
\text { (RS) }\end{array}$ & $\begin{array}{c}\text { Serviços de } \\
\text { terceiros (RS) }\end{array}$ & $\begin{array}{c}\text { Tarifas, } \\
\text { taxas, etc } \\
\text { (RS) }\end{array}$ & Transporte (RS) & $\begin{array}{c}\text { Formação } \\
\text { Profissional } \\
\text { (RS) }\end{array}$ & Outros (RS) & $\begin{array}{c}\text { Material } \\
\text { Permanente } \\
\text { (RS) }\end{array}$ & \\
\hline & $5.439,89$ & $3.023,30$ & 584,00 & 113,59 & & & & $1.719,00$ & \\
\hline \multirow{2}{*}{2007} & $5.445,20$ & \multicolumn{6}{|c|}{$4.356,20$} & $1.089,00$ & \multirow{2}{*}{1} \\
\hline & $5,445,20$ & $2.813,66$ & $1.522,00$ & 20,54 & & & & $1.089,00$ & \\
\hline \multirow{2}{*}{2008} & $5.361,00$ & \multicolumn{6}{|c|}{$4.288,80$} & $1.072,20$ & \multirow{2}{*}{1} \\
\hline & $5.361,00$ & $1.191,50$ & $2.473,00$ & & & & & $1.072,20$ & \\
\hline \multirow{2}{*}{2009} & $5.235,00$ & \multicolumn{6}{|c|}{$3.664,50$} & $1.570,50$ & \multirow{2}{*}{1} \\
\hline & 5235,00 & $1.191,50$ & $2.473,00$ & & & & & $1.570,50$ & \\
\hline \multirow{2}{*}{2010} & $5.208,00$ & \multicolumn{6}{|c|}{$2.078,88$} & $3.129,00$ & \multirow{2}{*}{1} \\
\hline & $5.208,00$ & 128,88 & $1.950,00$ & & & & & $3.129,00$ & \\
\hline \multirow{2}{*}{2011} & $10.438,06$ & \multicolumn{6}{|c|}{$4.175,56$} & $6.262,52$ & \multirow{2}{*}{2} \\
\hline & $10.438,06$ & $1.565,46$ & $2.610,00$ & & & & & $6.262,60$ & \\
\hline \multirow{2}{*}{2012} & $7.669,80$ & \multicolumn{5}{|c|}{$3.067,92$} & & $4.601,88$ & \multirow{2}{*}{1} \\
\hline & $7.669,80$ & $2.467,92$ & 600,00 & & & & & $4.601,88$ & \\
\hline \multirow{2}{*}{2013} & $15.007,38$ & \multicolumn{5}{|c|}{$7.503,69$} & & $7.503,69$ & \multirow{2}{*}{1} \\
\hline & $13.961,30$ & $5.983,30$ & 641,00 & & & & & $7.337,00$ & \\
\hline \multirow{2}{*}{2014} & $9.078,15$ & \multicolumn{5}{|c|}{$2.650,00$} & & $6.428,15$ & \multirow{2}{*}{1} \\
\hline & $9.078,15$ & 300,00 & $2.091,50$ & 258,50 & & & & $6.428,15$ & \\
\hline \multirow{2}{*}{2015} & $8.197,50$ & \multicolumn{5}{|c|}{$2.665,21$} & & $5.532,29$ & \multirow{2}{*}{1} \\
\hline & $7.925,14$ & $2.392,85$ & & & & & & $5.532,29$ & \\
\hline \multirow{2}{*}{2016} & $28.107,36$ & & & & $22.575,36$ & & & $5.532,00$ & 3 \\
\hline & $18.781,09$ & $4.096,66$ & $11.705,00$ & & & & & $2.979,43$ & 3 \\
\hline
\end{tabular}

Fonte: Elaborado pelos autores a partir dos dados levantados em campo e instrumento de Viana (2009; 2010; 2015).

Com base na tabela 8 é possível perceber que, na Escola B, o Programa Dinheiro Direto na Escola não foi usado para realização de excursão escolar (transporte) ou formação 
profissional em nenhum ano e que o uso dos recursos financeiros é em sua maior parte destinado a material de consumo, material permanente e serviços de terceiros. A Escola B, por se tratar de uma escola da rede estadual, conta com programas específicos que são destinados à locação de transporte escolar; dessa forma, pode ser que a escola tenha optado em realizar as excursões escolares com montantes transferidos pelo governo estadual, e não pelo PDDE. Nos anos de 2006, 2007 e 2014 a escola fez uso do PDDE para pagamento de tarifas, taxas e impostos como INSS e ISS.

Na maioria dos anos o montante do PDDE foi repassado somente uma vez, somente nos anos 2011 e 2016 a escola recebeu mais de um repasse do programa: 2 e 3, respectivamente. O ano de 2016 também é o ano em que a escola recebe o maior montante do PDDE durante o período pesquisado ( $\mathrm{R} \$ 28.107,36)$.

Somente no ano de 2015 a escola não utilizou a verba de custeio para despesas com Serviços de Terceiros. Em todos os outros anos a escola fez uso do PDDE para pagamento de despesas com serviços de terceiros e, no ano de 2016, cerca de metade do valor da Verba de Custeio foi utilizado para pagamento de serviços de terceiros. Isso pode ter acontecido porque no ano anterior a escola elevou o seu Índice de Desenvolvimento da Educação Básica (IDEB) e a Resolução $n^{\circ}$ 03, 01 de abril de 2012 determina uma parcela extra de $50 \%$ para as escolas que elevaram o seu IDEB.

Por fim, a tabela 9 mostra os valores dos montantes em reais nominais que a Escola $B$ deveria ter recebido segundo a Resolução FNDE $n^{\circ} 10$, de 18 de abril de 2013, o valor efetivamente recebido, o número de alunos, os valores fixos e per capita, planejados e recebidos.

Tabela 9 - Escola B a partir da Resolução FNDE n 10, de 18 de abril de 2013

\begin{tabular}{|c|c|c|c|c|c|c|}
\hline \multicolumn{6}{|c|}{ Escola B a partir da Resolução FNDE $\mathbf{n}^{\mathbf{1}} \mathbf{1 0}$, de $\mathbf{1 8}$ de abril de $\mathbf{2 0 1 3}$} \\
\hline Ano & $\begin{array}{c}\text { Valor } \\
\text { planejado }\end{array}$ & $\begin{array}{c}\text { Valor } \\
\text { recebido }\end{array}$ & $\begin{array}{c}\text { Número } \\
\text { de alunos } \\
\text { do ano } \\
\text { anterior }\end{array}$ & $\begin{array}{c}\text { Valor } \\
\text { Fixo }\end{array}$ & $\begin{array}{c}\text { Valor per } \\
\text { capita } \\
\text { planejado }\end{array}$ & $\begin{array}{c}\text { Valor per capita } \\
\text { recebido }\end{array}$ \\
\hline $\mathbf{2 0 1 3}$ & 14300,00 & 15007,38 & 665 & 1000,00 & 20 & 22,57 \\
\hline $\mathbf{2 0 1 4}$ & 14240,00 & 9078,15 & 662 & 1000,00 & 20 & 13,71 \\
\hline $\mathbf{2 0 1 5}$ & 13600,00 & 8197,50 & 630 & 1000,00 & 20 & 13,01 \\
\hline $\mathbf{2 0 1 6}$ & 13800,00 & 28107,36 & 640 & 1000,00 & 20 & 43,92 \\
\hline
\end{tabular}

Fonte: Elaborada pelos autores com dados levantados em campo.

Com base na tabela acima, é possível perceber que o valor previsto pela Resolução FNDE $n^{\circ} 10$, de 18 de abril de 2013 para a Escola B pelo PDDE nos anos de 2013 e 2016, foi menor do que o valor efetivamente recebido, isso implicou um valor per capita recebido, no ano de 2013 , de $R \$ 22,57$, sendo $R \$ 2,57$ acima do valor per capita planejado (como seria de se esperar pela soma da parcela fixa) e, no ano de 2016 , esse valor foi $R \$ 43,92$, ou seja, mais do que o dobro do valor per capita que a escola deveria ter recebido. No entanto, nos anos 2014 e 2015 a escola recebeu menos do que deveria. No ano de 2014 o valor per capita do montante recebido pelo PDDE foi de apenas $R \$ 13,71$ e, em 2015 , o valor per capita recebido foi $R \$ 13,01$. Ou seja, a escola recebeu por aluno em 2014 apenas $68,55 \%$ do valor planejado por aluno e, em 2015 , somente $65,05 \%$ desse valor. 
Montantes e Gastos Anuais de Escolas Públicas com os Recursos do PDDE

\section{Conclusões}

Dentre os achados da pesquisa, destaca-se que as escolas pesquisadas receberam apenas um repasse anual do PDDE (exceto na Escola B nos anos 2011 e 2016) e com valores de custeio e capital diferentes, já que na Escola A, por exemplo, apenas em um ano (2010) o valor para capital e custeio foram aproximados, sendo que, na Escola $B$, o repasse de capital chega a ultrapassar o de custeio $(2010,2011,2012,2014$ e 2015), o que demonstra que cada escola de fato solicitou por um percentual de repasse diferente para cada tipo de verba, conforme suas próprias demandas e de acordo com a possibilidade trazida pelo artigo $11 \mathrm{da}$ Resolução $n^{\circ} 10 / 2013$, o que representa maior autonomia na decisão sobre as prioridades de gastos da escola.

Os maiores valores de repasses recebidos através do PDDE por ambas as escolas foram nos anos de 2011, 2013 e 2016, havendo redução nos demais anos analisados pela série histórica. No entanto, como dito, a Escola A recebeu o repasse em parcela única anualmente, enquanto que a Escola B, em 2011, recebeu o repasse dividido em duas parcelas, e, em 2016, chegou a receber em três parcelas. As datas de repasse e valores diferentes do esperado podem prejudicar o planejamento da gestão dos recursos.

Em 2016, a Escola A registrou o maior valor recebido durante a pesquisa, sendo este de $\mathrm{R} \$ 35,75$ por aluno, com 468 alunos matriculados. A Escola $B$ recebeu o valor mais alto registrado no período pesquisado também no ano de 2016 , sendo este de $R \$ 45,33$ por aluno, com 620 alunos matriculados.

O ano de 2013 também foi um ano no qual as escolas receberam um montante alto do programa, talvez porque o PDDE teve o seu ápice de transferência às escolas públicas do País, quando alcançou a quantia de R $\$ 2,6$ bilhões (BRASIL, 2017).

Com relação ao menor valor recebido pelas escolas durante o período estudado, a Escola A recebeu, em 2010, $\mathrm{R} \$ 8,07$ por aluno, tendo 635 alunos matriculados. Já a Escola $B$ recebeu o menor valor por aluno no ano de 2006, sendo este de $R \$ 7,62$, com 715 alunos matriculados, no entanto, nos anos 2009 e 2010 a escola também registrou um valor baixo por aluno, $\mathrm{R} \$ 7,96$, com 658 alunos matriculados em 2009 e 654 alunos matriculados em 2010.

Com relação aos destinos dos montantes recebidos pelas escolas, foi possível perceber que ambas utilizaram a maior parte do montante recebido para pagamento das despesas com manutenção de bens imóveis da instituição escolar (tanto para gastos com serviços de terceiros quanto com material de infraestrutura) em detrimento de despesas de caráter pedagógico.

Dessa forma, o trabalho reitera e confirma análises já trazidas pelas contribuições feitas pelas pesquisas de Viana (2015), em que foi demonstrado que a maior parte dos gastos com o recurso do PDDE nas escolas é com manutenção; com Batista (2018), que destacou que os recursos do PDDE, embora permitam o fortalecimento das atividades pedagógicas e da infraestrutura da escola, são limitados; e com Mafassioli (2017), que caracterizou o programa PDDE Básico, muito utilizado para a manutenção de unidades, bem como suas dez modalidades e as (re)formulações em cada ciclo de governos. Essas contribuições colaboram com os estudos sobre gestão financeira escolar, já que apontam para uma melhor percepção dos recursos financeiros descentralizados para as escolas públicas no País. 
Montantes e Gastos Anuais de Escolas Públicas com os Recursos do PDDE

Além disso, este trabalho traz como contribuição um levantamento histórico do PDDE, que possibilita uma visão mais ampla sobre como o programa funciona em duas escolas de redes de ensino diferentes em São Paulo. Evidencia-se que, a partir do ano de 2014, as escolas deveriam receber dois repasses anuais, segundo a Resolução $n^{\circ} 05$ de 31 de março de 2014, no entanto, uma escola recebeu e a outra não. Também aqui se demonstrou que as escolas não receberam em todos os anos contemplados pela pesquisa o montante devido a partir do que é definido pela Resolução n 10, de 18 de abril de 2013.

\section{Referências}

BATISTA, Pablo. Descentralização financeira para as escolas da educação básica pública: uma análise do PDDE na escola estadual cidade modelo no período de 2012 a 2015. 2018. Dissertação (Mestrado em Educação) - Universidade Federal do Pará, Belém, 2018.

BRASIL. Ministério da Educação. FNDE Resolução n. 12, de 10 de maio de 1995. Dispõe sobre o PDDE. Brasília, 1995.

BRASIL. Medida Provisória $\mathrm{n}^{\circ}$ 1.784, de 14 de dezembro de 1998. Dispõe sobre o repasse de recursos financeiros do Programa Nacional de Alimentação Escolar, institui o Programa Dinheiro Direto na Escola, e dá outras providências. Diário Oficial da União, Brasília, 1998.

BRASIL. Medida Provisória $n^{\circ}$ 2.100-32, de 24 de maio de 2001. Dispõe sobre o repasse de recursos financeiros do Programa Nacional de Alimentação Escolar, institui o Programa Dinheiro Direto na Escola, altera a Lei $n^{\circ}$ 9.533, de 10 de dezembro de 1997, que dispõe sobre programa de garantia de renda mínima, institui programas de apoio da União às ações dos Estados e Municípios, voltadas para o atendimento educacional, e dá outras providências. Diário Oficial da União, Brasília, 2001.

BRASIL. Lei 11.494/07. Regulamenta a Emenda Constitucional n 53/06 e Lei n 11.494/07. Diário Oficial da União, Brasília, 2007a.

BRASIL. Ministério da Educação. Resolução nº 9, 24/4/2007 - Dispõe sobre PDDE. Brasília, 2007b.

BRASIL. Lei 11.947, de 16 de junho de 2009. PNAE. Dispõe sobre o atendimento da alimentação escolar e do Programa Dinheiro Direto na Escola aos alunos da educação básica; altera as Leis nos 10.880, de 9 de junho de 2004, 11.273, de 6 de fevereiro de 2006, 11.507, de 20 de julho de 2007; revoga dispositivos da Medida Provisória no 2.178-36, de 24 de agosto de 2001, e a Lei no 8.913, de 12 de julho de 1994; e dá outras providências. Diário Oficial da União, Brasília, 2009.

BRASIL. Ministério da Educação. Resolução no 10 de 18 de abril de 2013 - Dispõe sobre o PDDE. Brasília, 2013a.

BRASIL. Ministério da Educação. PDDE Programa Dinheiro Direto na Escola. Manual de orientações para as escolas. Brasília, 2013b.

BRASIL. Ministério da Educação. Resolução n5 de 31 de Março de 2014. Dispõe sobre o PDDE. Brasília, 2014.

BRASIL. Ministério da Educação. Resolução FNDE $n^{\circ}$ 6, de 27 de fevereiro de 2018. Acrescenta e altera dispositivos da Resolução CD/FNDE $n^{\circ} 10$, de 18 de abril de 2013, 
Montantes e Gastos Anuais de Escolas Públicas com os Recursos do PDDE

do Conselho Deliberativo do Fundo Nacional de Desenvolvimento da Educação. Brasília, 2018.

CAMARGO, Rubens. Gestão financeira escolar como política pública: análise de procedimentos legais e administrativos, processos participativos e montantes dos recursos financeiros destinados às escolas de redes públicas. Relatório Final de Pesquisa Regular FAPESP. São Paulo, 2012.

MAFASSIOLI, Andréia. Programa dinheiro direto na escola: (re)formulações e implicações na gestão escolar e financeira da educação básica (1995-2015). 2017. Tese (Doutorado em Educação) - Universidade Federal do Rio Grande do Sul, Porto Alegre, 2017.

VIANA, Mariana Peleje. Gestão financeira escolar como política pública: aplicação de instrumentos para levantamento de procedimentos legais e administrativos, processos participativos e montantes dos recursos financeiros destinados às escolas de redes públicas. Relatório Final de Pesquisa de Iniciação Científica FAPESP. São Paulo, 2009.

VIANA, Mariana Peleje. Gestão dos recursos financeiros descentralizados destinados às escolas públicas de São Paulo: seus montantes, processos participativos e procedimentos legais e administrativos envolvendo sua execução. 2010. Trabalho de Conclusão de Curso (Graduação em Pedagogia) - Faculdade de Educação, Universidade de São Paulo, São Paulo, 2010.

VIANA, Mariana Peleje. Recursos financeiros descentralizados para a escola pública: uma política necessária. 2015. Dissertação (Mestrado em Educação) - Faculdade de Educação, Universidade de São Paulo, São Paulo, 2015.

Clarissa dos Santos Bitencourth é graduanda em Pedagogia pela Faculdade de Educação da Universidade de São Paulo (2015-2019). Participou como Bolsista no Programa de Iniciação à Docência (PIBID FEUSP) no primeiro semestre de 2017. Atualmente integra o Centro de Estudos e Pesquisa em Políticas Públicas da Educação (CEPPPE), seu trabalho de pesquisa é intitulado Gestão financeira escolar como política pública: investigação sobre procedimentos legais e administrativos, processos participativos e montantes destinados às Escolas de Ensino Fundamental da Rede Municipal da Cidade de São Paulo (2007 a 2016), orientada pelo Professor Doutor Rubens Barbosa de Camargo.

ORCID: http://orcid.org/0000-0002-3709-2530

E-mail: csbitencourth@gmail.com

Fernanda Dayane Bezerra Gomes é graduanda em Pedagogia pela Faculdade de Educação da Universidade de São Paulo (2015-2019). Atualmente integra o Centro de Estudos e Pesquisa em Políticas Públicas da Educação (CEPPPE), seu trabalho de pesquisa é intitulado Gestão financeira escolar como política pública: investigação numa escola de ensino fundamental da rede estadual de São Paulo (2006 a 2016), orientada pelo Professor Doutor Rubens Barbosa de Camargo.

ORCID: http://orcid.org/0000-0001-8332-0680

E-mail: fernanda.dayane.gomes@usp.br 
Montantes e Gastos Anuais de Escolas Públicas com os Recursos do PDDE

Rubens Barbosa de Camargo possui graduação em Física pela Universidade de São Paulo (1981), Mestrado em Educação pela Universidade Estadual de Campinas (1989) e Doutorado em Educação pela Universidade de São Paulo (1997). Foi professor da Educação Básica na rede pública e privada em São Paulo (1978 a 1992). Atuou na gestão da Secretaria Municipal de Educação do Município (SME) de São Paulo de 1989 a 1992. Foi professor Assistente e Professor Adjunto do Departamento de Educação (DEd) do Centro de Educação e Ciências Humanas (CECH) da Universidade Federal de São Carlos (UFSCar) (1993-1998). Desde 1998 foi Professor Doutor do Departamento de Administração Escolar e Economia da Educação (EDA) da Faculdade de Educação da Universidade de São Paulo (Feusp). Obteve o título de Livre-Docente do EDA da FEUSP em 2018 (Professor Assistente I).

ORCID: http://orcid.org/0000-0002-1988-2934

E-mail: rubensbc@usp.br 


\section{Editores do volume 10}

Márcia Aparecida Jacomini - Universidade Federal de São Paulo, Brasil

José Marcelino de Rezende Pinto - Universidade de São Paulo, Brasil

\section{Comitê Editorial}

Nalú Farenzena - Universidade Federal do Rio Grande do Sul, Brasil

Juca Gil - Universidade Federal do Rio Grande do Sul, Brasil

Theresa Adrião - Universidade Estadual de Campinas, Brasil

Ângelo Ricardo de Souza - Universidade Federal do Paraná, Brasil

\section{Conselho Editorial}

\section{Alejandro Morduchowicz}

Universidad Pedagógica, Provincia de Buenos Aires, Argentina

Andréa Barbosa Gouveia

Universidade Federal do Paraná, Brasil

Fernanda Saforcada

Universidade de Buenos Aires, Argentina

Jacques Velloso

Universidade de Brasília, Brasil

João Monlevade

Senado Federal, Brasil

Jorge Abrahão de Castro

Instituto de Pesquisa Econômica Aplicada / IPEA, Brasil

Lisete Regina Gomes Arelaro

Universidade de São Paulo, Brasil

Luis Carlos Sales

Universidade Federal do Piauí, Brasil

Luiz de Sousa Junior

Universidade Federal da Paraíba, Brasil

Luiz Fernandes Dourado

Universidade Federal de Goiás, Brasil

Magna França

Universidade Federal do Rio Grande do Norte, Brasil

Marcos Edgar Bassi

Universidade Federal de Santa Catarina, Brasil

Maria Angélica Pedra Minhoto

Universidade Federal de São Paulo, Brasil

Maria Beatriz Luce

Universidade Federal do Rio Grande do Sul, Brasil

Maria Dilnéia Espíndola Fernandes

Universidade Federal de Mato Grosso do Sul, Brasil

Nelson Cardoso do Amaral

Universidade Federal de Goiás, Brasil

Nicholas Davies

Universidade Federal Fluminense, Brasil

Robert E. Verhine

Universidade Federal da Bahia, Brasil

Romualdo Portela de Oliveira Universidade de São Paulo, Brasil

Rosana Gemaque Rolim

Universidade Federal do Pará, Brasil

Rubens Barbosa de Camargo

Universidade de São Paulo, Brasil

Theresa Adrião

Universidade Estadual de Campinas, Brasil

Tristan McCowan

University of London, Reino Unido

Vera Jacob

Universidade Federal do Pará, Brasil

Vera Peroni

Universidade Federal do Rio Grande do Sul, Brasil

Vitor Henrique Paro

Universidade de São Paulo, Brasil

\section{Equipe editorial}

Apoio ao Comitê Editorial: Caio Cabral da Silva

Diagramação, Revisão de português e normalização: Edson Leonel de Oliveira

Revisão de inglês: Ananyr Porto Fajardo

Fineduca - Revista de Financiamento da Educação

Associação Nacional de Pesquisa em

Financiamento da Educação

e-mail: revista.fineduca@gmail.com | site: http://seer.ufrgs.br/fineduca 